\title{
Importancia de la utilización del diccionario en contextos áulicos paraguayos
}

\section{Importance of the use of the dictionary in Paraguayan aulic contexts}

\author{
* Peralta de Aguayo, E.M. ${ }^{1}$ \\ ${ }^{1}$ Universidad del Cono Sur de las Américas, Asunción, Paraguay
}

\section{RESUMEN}

Una indagación a los alumnos de los primeros ciclos universitarios ha reflejado un desconocimiento de su macro y microestructura, así como en la fluidez de la búsqueda de los vocablos y en la selección del significado apropiado al contexto. Por ello se analiza la importancia y necesidad de incluir la utilización del diccionario en los contextos áulicos paraguayos, así como la inclusión de esta capacidad en los programas de estudio del Ministerio de Educación y Cultura. Desde la perspectiva de la lexicografía escolar, se esbozan algunos lineamientos para la utilización del diccionario en las aulas.

Palabras clave: diccionario escolar; uso del diccionario; contexto áulico paraguayo.

El diccionario, viejo y pesado, con su chaquetón de pellejo gastado, se quedó silencioso

sin mostrar sus probetas [...] Pablo Neruda

\begin{abstract}
A research among the students of the first university cycles has reflected an ignorance of their macro and microstructure, as well as the fluidity in the search for words and the selection of appropriate meaning to the context. Therefore, the importance and necessity of including the use of the dictionary in Paraguayan contexts and the inclusion of this capacity in the curricula of the Ministry of Education and Culture are analyzed. From the perspective of school lexicography, some guidelines are outlined for the use of the dictionary in classrooms.
\end{abstract}

Keywords: school dictionary; dictionary use; Paraguayan aulic context.

\section{INTRODUCCIÓN}

El diccionario es un instrumento fundamental en el proceso de adquisición y aprendizaje de una lengua. En los últimos tiempos se ha observado su infrautilización en la aulas, prácticamente ha caído en desuso, la experiencia docente ha revelado que los alumnos del primer año de las universidades paraguayas no poseen un diccionario y en caso que cuenten con alguno, resulta que ha sido elaborado hace 20 o más años atrás, por ejemplo, aquellos en que la ordenación se realizaba incluyendo los dígrafos ch, II, lo cual la Asociación de

*Autor Correspondiente: Estela Mary Peralta de Aguayo. UCSA. Paraguay E-mail: eperalta@ucsa.edu.py

Fecha de recepción: setiembre 2016; Fecha de aceptación: octubre 2016. 
Academias de la Lengua Española ${ }^{1}$ en el X Congreso de Academias de la Lengua Española celebrado en 1994. Sumado a esta carencia se percibe la dificultad que poseen para emplearlo.

Cassany (2002) sostiene que «el conocimiento que ofrecen las informaciones que ofrecen los diccionarios y su utilización proporciona un grado de autonomía muy elevado». Con el mismo pensamiento, Prado Aragonés (2005) destaca que «la autonomía permite al alumno dirigir su adquisición de la lengua hacia sus objetivos concretos», lo que conlleva a determinarla relevancia del aprendizaje del uso del diccionario por parte de los hablantes.

Esta reflexión surge tras una breve indagación, sobre 150 alumnos en el primer semestre de una universidad paraguaya del año 2016, sobre el manejo del diccionario. Para lo cual se había solicitado a los alumnos que trajeran un diccionario para utilizarlo en clase, lo cual no fue exitoso, del total solo 10 alumnos lo trajeron y el resto no, de los ejemplares observados estos eran de los años 90, otros un poco más actuales, aquellos que el Ministerio de Educación y Cultura, MEC, concedía en los kits escolares, por lo general, el ministerio selecciona obras abreviada de un diccionario mayor, ante esa dificultad $y$, como es más evidente que los alumnos cuentan con teléfonos celulares y no con diccionarios, se les solicitó que bajaran la aplicación del Diccionario de la lengua española para utilizarlo en el aula.

Para la observación, tan solo nos ceñimos al manejo del diccionario, esto es, la búsqueda de la palabra, conocimiento de la información gramatical, formas complejas y la selección del término apropiado según el contexto. Los resultados de esta observación arrojaron que casi el $90 \%$ de los alumnos desconocen qué información gramatical ofrecen, el significado de las abreviaturas y signos. Además, se percibe la dificultad en la búsqueda de verbos. Asimismo, a la hora de seleccionar el significado de la palabra estudiada, por lo general, se decantan por la primera acepción en aquellos lemas polisémicos.

Estos resultados nos llevan a la reflexión de la importancia e imperante necesidad de utilizar los diccionarios en las aulas de la educación básica y media, pues colegimos que se hubiera tenido un buen dominio del uso este instrumento lexicográfico en las aulas universitarias si no se lo hubiese infrautilizado en 13 años de escolarización previa.

Destacamos que en el Paraguay aún no hay estudios al respecto, para el análisis nos ceñimos a los lineamientos de la lexicografía didáctica.

\section{Punto de partida: qué diccionario utilizar}

Para determinar qué diccionario se debe emplear, primeramente, se debe asumir que «un diccionario no es para toda la vida; un diccionario no sirve para todo $y$ todos los diccionarios no son iguales» Maldonado (2008, p. 11). Existe una inmensa variedad de diccionarios, los generales que recogen un número alto de voces de la lengua y tratan de reflejar todos los usos de esta, por ejemplo, el Diccionario de la Lengua Española (2014) de la Real Academia

\footnotetext{
${ }^{1} \mathrm{Al}$ tratarse de combinaciones de dos letras, las palabras que comienzan por estos dígrafos o que los contienen no se alfabetizan aparte, sino en los lugares que les corresponden dentro de la $c$ y de la $I$, respectivamente. La decisión de adoptar el orden alfabético latino universal se tomó en el X Congreso de la Asociación de Academias de la Lengua Española, celebrado en 1994, y viene aplicándose desde entonces en todas las obras académicas. Fuente: http://www.rae.es/consultas/exclusion-de-ch-y-II-del-abecedario. Fecha de consulta: $11 / 6 / 16$
} 
Española y la Asociación de Academias de la Lengua Española, los diccionarios ideológicos, cuya ordenación se parte de un rasgo ideológico o una idea; de sinónimos y antónimos, de frases entre otros. Estos diccionarios son útiles, pero no se podrá pedir al alumno que cuente con cada tipo de diccionario, sin embargo, es importante que la biblioteca de la institución educativa posea en su caudal bibliográfico con dichos materiales y sea el docente quien incluya en su planificación la utilización y explicación de estos.

Aquí, nos centraremos en los diccionarios de carácter didáctico, especialmente el escolar; pues no todos los diccionarios son semejantes ni se destinan a un mismo público. La lexicografía didáctica es aquella que se ocupa de dos ámbitos: a) los que tienen como fin apoyar la enseñanza de la lengua materna: los diccionarios escolares y b) aquellos destinados al aprendizaje de lenguas extranjeras: diccionarios monolingües de aprendizaje, esto Azorín ${ }^{2}$ (2000) lo grafica de la siguiente manera (Cuadro 1):

Cuadro 1. Tipología de diccionarios didácticos. Azorín (2000, p. 22.).

\begin{tabular}{cc}
\hline \multicolumn{2}{c}{ Diccionario didáctico } \\
Objetivo: enseñanza/aprendizaje de lenguas \\
\hline $\begin{array}{c}\text { Diccionario escolar } \\
\text { Enseñanza/aprendizaje de la lengua } \\
\text { materna }\end{array}$ & $\begin{array}{c}\text { Diccionario de aprendizaje } \\
\text { Enseñanza/aprendizaje de la lengua } \\
\text { extranjera }\end{array}$ \\
\hline
\end{tabular}

Asimismo, Hernández propone una clasificación desde la perspectiva del usuario (Cuadro 2):

Cuadro 2. Tipología de diccionarios según el tipo de usuario. Adaptado de Hernández (1993, p. 193).

\begin{tabular}{ll}
\hline \multicolumn{1}{c}{ Clases de usuarios } & \multicolumn{1}{c}{ Tipos de Diccionarios } \\
\hline $\begin{array}{l}\text { Usuarios con conocimiento y } \\
\text { dominio del idioma. }\end{array}$ & Diccionarios generales, usuales y manuales. \\
Usuarios en fase de aprendizaje & $\begin{array}{l}\text { De la segunda lengua: diccionarios bilingües y } \\
\text { diccionarios monolingües para usuarios } \\
\text { extranjeros materna: diccionarios escolares. } \\
\text { De la lengua maternation }\end{array}$
\end{tabular}

Prado (2000) propone una tipología según la relación: docente-alumno, a saber: Diccionarios infantiles, de 0-8 años: estos deben desarrollar aspectos como la lateralidad, memoria visual y elementos del proceso de lectoescritura. Por lo que deben elaborarse con una tipografía adecuada, incluir ilustraciones ${ }^{3} y$, en especial, el vocabulario recogido debe ser reducido. Es importante que el niño se aproxime al diccionario ya desde esta etapa, la nomenclatura debería contener elementos de la

\footnotetext{
${ }^{2}$ Azorín Fernández (2000). Los diccionarios didácticos del español desde la perspectiva de sus destinatarios. En L.U.A., 14, 2000, pp. 19-44.

${ }^{3}$ Ejemplo de esto el Nuevo diccionario imaginario (2001) o Imaginario: Diccionario en imágenes (2005) elaborados por Concepción Maldonado para la Editorial SM, que reúnen aproximadamente 1500 palabras definidas con imágenes.
} 
realidad próxima de los alumnos, en «núcleos conceptuales o temas», Prado Aragonés (2005).

- Diccionarios escolares, de 8-12 años ${ }^{4}$ : los destinatarios son los alumnos de la primaria o EEB, en nuestro caso $1 .^{\circ}$ y $2 .^{\circ}$ ciclos y parte del 3.er ciclo, su diseño debe construirse con criterios didácticos de acuerdo con la edad y el nivel escolar de los destinatarios. Esta etapa envuelve a los diccionarios denominados escolares o didácticos, los deben contener las palabras para resolver las necesidades lingüísticas e informativas de los estudiantes.

Aquellas obras elaboradas bajo esta franja etaria deben ser observados bajo la lupa antes de adquirirlos, ya que muchos no son tan didácticos o escolares como manifiestan en sus denominaciones ${ }^{5}$, pues existen obras que son meras reducciones de una mayor, a los que se les han quitado artículos, para hacerlos manos profusos.

- Diccionarios para la enseñanza de la lengua, diccionarios de uso y diccionarios normativos, de 12-16 años, debe incluir un léxico usual, notas sobre la pronunciación, definiciones de fácil comprensión el número de ejemplos deber ser profuso; asimismo debe incluir información de tipo gramatical y normativo, sinónimos y antónimos, y apéndices que complementen y aclaren elementos contenidos en el cuerpo del diccionario.

Sumado a esto, Maldonado (2000) establece unos criterios que se tienen en cuenta a la hora de seleccionar los diccionarios: el peso y tamaño de estos, lo cual es fundamental en el caso de los escolares ya que se transportarán en la mochila y uno pesado hará más difícil su traslado; su presentación en uno o varios tomos, lo cual complica la búsqueda; el tipo de encuadernación, puesto su manejabilidad es primordial para el uso; el tipo de papel empleado, ya que si se emplea un papel fino se podrán incluir más entradas, sin que ello suponga una buena calidad del papel empleado; por último: el precio, lo cual, en ocasiones determina la compra.

Añadido a las razones anteriores, que son puramente físicas, la autora explica que el diccionario debe reunir otras características, como el corpus empleado, esto es, de dónde se obtuvieron las palabras para su elaboración; la calidad de las definiciones; la inserción o no de ejemplos; la inclusión sobre aspectos gramaticales; la actualización. Asimismo, remarca que también influye la decisión editorial de incluir o no aquellas palabras contenidas en la última versión Diccionario de la lengua española de la Real Academia Española y, por último, debe contemplarse el componente ideológico subyacente en las obras.

Prado Aragonés (2005), por su parte, coincide con Maldonado, mas también acrecienta otros ítems para la valoración de las obras de esta cala, como la inserción del léxico usual, que las definiciones contengan palabras definidas en el diccionario, es decir, sin pistas perdidas, que las abreviaturas y símbolos empleados sean comprensibles.

\footnotetext{
${ }^{4}$ La editorial SM es una de las más productivas en este tipo de productos lexicográficos: Diccionario básico de la lengua española. Primaria, para chicos de 8 a 12 años, dirigido por Concepción Maldonado.

${ }^{5}$ Hernández (2012, p. 276) sobre estos diccionarios refiere: «En realidad, muchos de los que suelen considerarse como didácticos generales no son tales, pues constituyen una simple reducción inorgánica de los grandes; son más bien diccionarios de menor contenido macro y microestructural con escasas características propias de la ya bien definida lexicografía didáctica».
} 


\section{El diccionario: una obra con arquitectura propia}

Un diccionario es una obra compleja, su elaboración, en ocasiones, lleva décadas. Es un producto que comprende el léxico de la comunidad en que es gestado, por tanto, responde a un contexto espacial y temporal determinado. Esto demuestra que es una obra demarcada en ciertos límites, no abarca todo el caudal léxico de la lengua que toma en estudio y tampoco aborda todas las variaciones que ella posee ni tampoco todos los campos del conocimiento.

La lengua se metamorfosea y es el léxico el elemento más susceptible a la evolución, esto obedece a que las realidades que nos envuelven desaparecen, mutan o surgen nuevas ${ }^{6}$. En los diccionarios de la década de los años 80 no hallaremos; wasap, tunear, wifi, porque la realidad es otra. Asimismo, en un diccionario actual no hallaremos telecinematógrafo, porque ha caído en desuso.

Su estructura se rige por algunos parámetros, desde la fuente de obtención de las palabras, la organización de las entradas, al igual que la manera en se organizan las acepciones, la información gramatical que proporciona, así como las informaciones de uso. Es decir, se ciñe a ciertos convencionalismos, que hacen que su estructura sea diferente a cualquier otro "libro" que se emplean en las aulas.

El diccionario posee un diseño propio, generalmente, se compone de elementos básicos: Lema = palabra entrada+ información gramatical + definición + marcas de uso + remisiones. Al mismo tiempo, es una obra que responde a una tipología textual, esto es un género textual y discursivo, según sus características formales y función.

\section{El docente como facilitador del uso del diccionario en las aulas}

Salvador (1992) sostiene que «una de las principales tareas del profesor consiste en «enseñar a manejar los diccionarios, toda clase de diccionarios, e ilustrar e informar sobre ellos, valorarlos, señalar las ventajas e inconvenientes de unos y de otros, guiar al alumno en el mare-mágnum lexicográfico». Alvar (1993) manifiesta que la infrautilización del diccionario en las aulas se debe al desconocimiento por parte de los docentes de las múltiples utilidades pedagógicas, así como las innumerables informaciones que podrían hallarse en sus páginas. Este acto podría deberse a que la formación docente haya sido deficiente en cuanto a información lexicográfica. Para el efecto, Alvar (1993) recomienda que los lexicógrafos inserten en sus páginas informaciones claras y precisas sobre el contenido en general de los diccionarios, es la única manera en que pueda obtenerse de él todas sus ventajas.

Al mismo tiempo, el docente debe conocer la oferta editorial existente y orientar al alumno (o a los padres en las etapas iníciales) sobre qué tipo de diccionario debe adquirir, ya que debe condecir con su nivel y necesidades. Está en sus manos la inclusión y creación de actividades que incluyan el empleo del diccionario, estas deben ser lo más atractivas posibles.

Debemos desterrar, la tradición arraigada en las aulas a las actividades de resolución de dudas ortográficas y búsquedas de palabras cuyos significados sean desconocidos a fin de incrementar el caudal léxico de los estudiantes, ambas cuestiones son útiles, sin embargo, hay que enriquecerlas, Maldonado (1998, p. 16).

Prado Aragonés (2005) expone lo siguiente con respecto a la escasa utilización del diccionario en el aula:

\footnotetext{
${ }^{6}$ De a que tenemos, vigencia, mortandad léxica.
} 
El profesor considera que es un instrumento que hay que tener próximo, pero que solo hay que consultar como último recurso para resolver dudas esporádicas, que en muchas ocasiones tampoco se resuelve porque no se consulta el diccionario adecuado. Se considera un recurso más apropiado para la enseñanza de la lengua escrita y se le asigna una función de consulta descifradora bastante limitada: buscar el significado de alguna palabra desconocida, consultar alguna acepción poco usual de otra, comprobar la ortografía dudosa de alguna otra, pero poco más.(Prado Aragonés, 2005a, p.23).

Siendo así, un diccionario escolar tendría que ir más allá de 'encontrar'7 las palabras, el hallazgo no es lo único que se concreta, luego de ese paso es preciso entender lo que qué es esa palabra y utilizarla apropiadamente. Allí, radica la riqueza de uso, el conocimiento de las palabras y su adecuación al contexto comunicativo otorga al hablante un dominio del lenguaje, recordemos las palabras de Pedro Salinas: «el hombre se posee a sí mismo a medida que posee su lenguaje».

\section{Bondades y dificultades del uso del diccionario en el contexto áulico}

El diccionario, ya lo dijimos más arriba, coadyuva el aprendizaje independiente, además permite: conocer el significado de las palabras; ampliar su vocabulario; esclarecer dudas sobre la ortografía de las palabras; adecuar las palabras a una situación comunicativa determinada; comprender el sentido figurado de palabras, expresiones, frases hechas, etc.; conocer la pronunciación de las palabras; buscar sinónimos y antónimos; consultar variedades, registros, usos, etc.

Según Prado Aragonés (2005) además de los conocimientos de carácter lingüístico, también existen informaciones de índole cultural, lo que permite comprender mejor la realidad, concebir una idea más clara de lo definido por medio de palabras y así formarse científicamente, puesto que el diccionario escolar recoge datos enciclopédicos, tecnicismos, entre otros.

Así como posee bondades, también tiene sus desventajas, si el diccionario es de formato en papel puede que sea dificultoso su manejo, la búsqueda de palabras lleva tiempo y por ello se lo aparta de las actividades áulicas. Además, ocurre que en aquellas palabras que contienen varias acepciones los alumnos seleccionan la primera y esta tal vez no responda al contexto de empleo de la palabra buscada; igualmente, puede que el tipo de diccionario adquirido por el alumno no sea adecuado para su edad y nivel escolar; otra situación sería que las informaciones contenidas en los diccionarios no son las que el estudiante busca. En las últimas décadas, se ha incursionado en la elaboración de diccionarios electrónicos, los cuales agilizan la búsqueda de palabras, pero unaspecto negativo es que posibilita que el alumno se retraiga.

Por consiguiente, es primordial cultivar todas las cualidades positivas del diccionario y en cuanto a lo negativo, es posible subsanarlo otorgando una información apropiada a los alumnos sobre el tipo y selección de las palabras y

\footnotetext{
${ }^{7}$ Maldonado (1988, p. 16) dice: «un diccionario no es, pese a la tradición del uso de diccionario que aún se arrastra en las aulas, encontrar una palabra, sino que igualmente importante es entenderla[...]».
} 
lo que refiere al uso del formato en papel o el electrónico es una tarea sencilla que un buen docente sabrá como zanjarla.

\section{Algunas actividades áulicas}

Alvar Esquerra (2003) manifiesta que el diccionario es empleado fundamentalmente en las siguientes actividades: a) la decodificación escrita (lectura); codificación escrita (escritura); c) decodificación oral (comprensión oral); codificación oral (expresión oral); decodificación de una L2 (traducción de L2 a L1) y la codificación de L2 (traducción de la L1 a L2). Del mismo modo, resalta que el uso por parte de los alumnos dependerá de las consignas dictadas por el docente. De ahí, que es primordial que este conozca los diccionarios y esté al tanto de lo que puede obtener de ellos.

Maldonado (1998) plantea diversas actividades por etapas, para primaria, bachillerato y ESO, lo que se adecua a los espacios de $1 .^{\circ}$ y $2 .^{\circ}$ ciclos de la Enseñanza Escolar Básica, EEB, la primera, y del $3 .{ }^{\text {er }}$ ciclo de la EEB y Educación Media, la segunda, en el contexto escolar paraguayo. En los primeros ciclos de la EEB, se da el primer contacto del alumno con el diccionario, en especial, la enseñanza de su uso, según Maldonado (1998), no solo debe ceñirse a «que es un libro de consulta que está ordenado alfabéticamente y que explica el significado de las palabras», pues más adelante descubrirá que estos aspectos se diluyen ya que existen diccionarios digitales, o sea, no siempre es un libro, algunos diccionarios no se ordenan alfabéticamente y que no siempre contienen todos los significados.

Al contrario, se debe destacar su importancia para el aprendizaje del significado desconocido de las palabras, al respecto, igualmente es necesario y primordial resaltar la que no debe confundir los significados de palabras parecidas. El estudiante debe saber qué informaciones contiene, para qué sirve y cómo se le emplea. Lo cual propiciará el aprendizaje autónomo por parte de ellos.

En el primer contacto, el alumno se enfrentará a una estructura diferente a los demás libros: estará divido en columnas; que la palabra buscada está resaltada en negritas, que posee una serie de abreviaturas antes del significado. Tanto Maldonado (1988) y Prado Aragonés (2005b) plantean una actividad de descubrimiento del diccionario que ambas denominan: ¿cómo es $\mathrm{mi} / \mathrm{tu}$ diccionario?, en que se aproxima al alumno al conocimiento físico del diccionario, su tamaño, forma, tipo de papel, verificación del tipo de imágenes (si contienen); tipos de abreviaturas y símbolos, forma de separación de acepciones, el contenido de las secciones preliminares, los apéndices entre otras.

Fontanillo Merino (1983), Maldonado (1998); Alvar Esquerra (2003) y Prado Aragonés (2005) proponen actividades para el empleo del diccionario en el aula, de manera sucinta las esgrimimos.

En los primeros estadios, es primordial que sean actividades vinculadas con el uso, inicialmente, habrá que reforzar la ordenación alfabética, los niños deben manejar el abecedario, así también hay que orientarlos en el uso de las palabras guías, por ejemplo:

- Dar un listado alfabético de palabras de diversos campos y ellos las busquen.

- Que oralmente cada alumno diga una palabra que se inicie por una letra y luego la siguiente... 
- Ofrecer una lista temática en que falten algunas letras, a fin de que completen las que faltan y luego las ordene alfabéticamente.

- Ordenar los nombres y apellidos de los compañeros de clase.

- Asignar un número a cada letra, a fin de que elaboren mensajes numéricos cifrados.

Según Maldonado (1999, p.28) a partir de los 8 años ya los alumnos «deben comparar, consultar, corregir y enmendar las palabras», esa franja etaria corresponde primer ciclo de la Educación Escolar Básica del Paraguay ${ }^{8}$. En los programas de los grados referidos a este ciclo no hemos hallado una referencia al uso del diccionario. Ya en el $2 .^{\circ}$ ciclo descubrimos las siguientes capacidades en las cuales se incluye su uso (Cuadro 3):

Cuadro 3. Unidades temáticas y capacidades del $2 .^{\circ}$ ciclo en que se incluye el uso del diccionario el currículum nacional. Lengua materna castellana. Elaboración propia.

\begin{tabular}{|c|c|c|}
\hline Grado & $\begin{array}{c}\text { Unidad } \\
\text { temática }\end{array}$ & Capacidades \\
\hline $4 .^{\circ}$ & $\begin{array}{l}\text { Comprensión } \\
\text { de textos } \\
\text { escritos }\end{array}$ & $\begin{array}{l}\text { «Identifica el significado de vocablos } \\
\text { desconocidos a través del contexto, del uso del } \\
\text { diccionario o reconociendo sinónimos y } \\
\text { antónimos». MEC. Programa de Estudio del } 4 .^{\circ} \\
\text { Grado (s.a., p. 234). }\end{array}$ \\
\hline $5 .^{\circ}$ & $\begin{array}{l}\text { Comprensión } \\
\text { de textos } \\
\text { escritos }\end{array}$ & $\begin{array}{l}\text { «Identifica el significado de vocablos desconocidos a } \\
\text { través del contexto, el uso del diccionario, el } \\
\text { reconocimiento de sinónimos y antónimos, y la } \\
\text { agrupación de vocablos según familias léxicas». MEC. } \\
\text { Programa de Estudio del } 5 .^{\circ} \text { Grado (s.a, p. 234). }\end{array}$ \\
\hline $6 .^{\circ}$ & $\begin{array}{l}\text { Comprensión } \\
\text { de textos } \\
\text { escritos }\end{array}$ & $\begin{array}{l}\text { «Aplica técnicas para aclarar vocablos desconocidos: } \\
\text { recurrir al contexto, usar el diccionario, recurrir a la } \\
\text { etimología, buscar sinónimos, antónimos». MEC. } \\
\text { Programa de Estudio del } 6 .^{\circ} \mathrm{Grado} \text { (s. a., p. 240) }\end{array}$ \\
\hline
\end{tabular}

El cuadro denota que la inclusión del diccionario se ciñe al contexto de la comprensión escrita y la capacidad de identificación del significado de vocablos desconocidos, solo se potencia una de las habilidades lingüísticas, específicamente la función decodificadora.

En estos grados, las actividades deberían, según Maldonado (1998), centrarse en el desarrollo de las destrezas de comprensión y expresión escrita, trabajar la polisemia, familia de palabras, la ortografía de las palabras, variaciones ortográficas (el caso de la pluralización), acentuación de palabras, de esta manera se irá fortaleciendo la enseñanza del uso del diccionario.

En el 3. ${ }^{\text {er }}$ ciclo de la EEB y el Nivel Medio, si bien el alumno ya debería ser diestro en el uso del diccionario, el docente no debe dar por sentado un buen dominio por parte de los estudiantes, por ende, siempre habrá que partir de una

\footnotetext{
${ }^{8}$ El ministerio de Educación y Cultura plantea como competencia del área de Comunicación del 1.er Ciclo en lengua materna que los alumnos: «Comprendan y produzcan textos orales $y$ escritos que se caractericen por utilizar un lenguaje con vocabulario básico, estructuras sintácticas sencillas y por abordar temas acordes su madurez cognitiva, a sus intereses y a sus necesidades». MEC (s.a, p. 51).
} 
evaluación al respecto. Maldonado (1998) propone que esta valoración se centre en la rapidez de búsqueda, en el hallazgo de las locuciones dentro del artículo apropiado o de las palabras homónimas y si acostumbran a leer las indicaciones de las secciones preliminares. Igualmente, es muy importante que esta evaluación se realice al inicio de cada curso, pues solamente así se cimentarán los puntales para una adecuada interpretación y utilización de la información que el diccionario puede ofrecer.

La evaluación previa permitirá al docente organizar sus planificaciones, ajustar aquellas dificultades y potenciar las habilidades ya desarrolladas. El diccionario tendrá que ir presentándose como un instrumento lingüístico que no solo se resume a la clarificación de dudas ortográficas; sino que reúne un cúmulo de informaciones ortográficas, morfológicas, sintácticas y pragmática y si el docente demuestra al estudiante que en él están las respuestas, el alumno, cuando haya tomado dominio del manejo del diccionario y haya conocido lo que este contiene en sus páginas y se apropie de esa práctica, irá logrando su autonomía y, en consecuencia, podrá construir su propio conocimiento.

En el currículum nacional del tercer ciclo de la EEB se plantean las siguientes capacidades para el área de Lengua y Literatura Castellana (Cuadro 4):

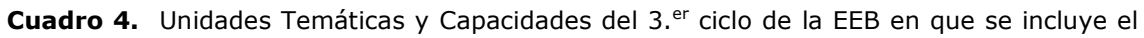
uso del diccionario el currículum nacional. Lengua materna castellana. Elaboración propia.

\begin{tabular}{|c|c|c|}
\hline Grado & Unidades Temáticas & Capacidades \\
\hline 7.0 & $\begin{array}{l}\text { Comprensión de } \\
\text { textos orales }\end{array}$ & $\begin{array}{l}\text { Comprende el sentido de vocablos y } \\
\text { expresiones de textos escuchados: } \\
\text { - } \quad \text { sinónimos y antónimos } \\
\text { - familia léxica. } \\
\text { - Inferencia por el contexto. } \\
\text { - uso del diccionario }\end{array}$ \\
\hline $8 .^{\circ}$ & $\begin{array}{l}\text { Comprensión de } \\
\text { textos orales }\end{array}$ & $\begin{array}{l}\text { Comprende el sentido de vocablos y } \\
\text { expresiones de textos escuchados: } \\
\text { - sinónimos y antónimos } \\
\text { - } \quad \text { familia léxica. } \\
\text { - Inferencia por el contexto. } \\
\text { - uso del diccionario. }\end{array}$ \\
\hline $9 .^{\circ}$ & $\begin{array}{l}\text { Comprensión de } \\
\text { textos orales }\end{array}$ & $\begin{array}{l}\text { Analiza el significado contextual de } \\
\text { vocablos y las relaciones semánticas } \\
\text { establecidas entre ellos, en textos } \\
\text { escuchados: } \\
\text { - } \text { sinónimos. } \\
\text { - antónimos. } \\
\text { - } \quad \text { campo semántico. } \\
\text { - inferencia por el contexto. } \\
\text { - uso del diccionario. } \\
\text { hipónimos - hiperónimos }\end{array}$ \\
\hline $9 .{ }^{\circ}$ & $\begin{array}{l}\text { Comprensión de } \\
\text { textos escritos }\end{array}$ & $\begin{array}{l}\text { Analiza los rasgos más resaltantes de los } \\
\text { siguientes tipos de textos: } \\
\text { - Informativos: } \\
\text { contenidas en informaciones } \\
\text { enciclopedias y revistas sobre } \\
\text { temas de interés. }\end{array}$ \\
\hline
\end{tabular}

En este ciclo capacidades se proyecta el uso del diccionario a la comprensión de textos orales, específicamente al análisis de los vocablos. Mientras que en el noveno grado se incluyen dos macrohabilidades lingüísticas: la comprensión oral 
y escrita. También se visualiza el uso del diccionario en su función decodificadora.

En esta etapa las actividades se deben perfilar de acuerdo con el grado o curso, según los contenidos y las capacidades a desarrollar. Se esbozan actividades de ortografía y pronunciación, como los casos de acentuación; ejercicios propios de la morfología: derivación, composición y parasíntesis, uso de siglas y acrónimos; flexión nominal y verbal. Ejercicios de sintaxis, para determinar la combinatoria de las palabras en la oración, uso de los elementos de enlace; ejercicios sobre el léxico: homonimia, polisemia, extranjerismos y los vinculados con la variación diastrática, diafásica y diatópica.

\section{CONCLUSIÓN}

Se vuelve necesario rescatar el valor del uso del diccionario en el aula, es una herramienta que facilita los procesos de aprendizaje. Su empleo está sujeto a la tarea docente, en primer lugar, la forma en que se plantee la enseñanza del uso del diccionario determinará el tipo de relación que mantendrá el alumno con este. En segundo término, será el docente quien propicie los espacios para su uso, las actividades son múltiples e infinitas. Así también, es necesario que oriente a los alumnos acerca de las ofertas editoriales existentes, que estas condigan con su edad, que sean útiles en cuanto su contenido, manejabilidad, tipo papel empleado, encuadernación y a valorar la relación entre calidad y precio. Finalmente, es una tarea docente internalizar en los alumnos las ventajas de su uso y su incidencia en el aprendizaje de ellos.

Queda latente una reflexión del currículum nacional en cuanto a la proyección del uso del diccionario en los contextos áulicos, ya que, como eje vertebrador de la concreción de las planificaciones de los docentes, al contemplar el uso del diccionario en el desarrollo de las capacidades decodificadoras de manera fragmentada, es decir, en un nivel se apunta lo escrito y en otro a lo oral y solamente en último grado del EEB se incluyen ambas habilidades de comprensión, oral y escrita. De igual manera, queda pendiente la inserción del uso del diccionario para el desarrollo de las capacidades de expresión oral y escrita, lo que apunta a la función codificadora del diccionario.

\section{REFERENCIAS BIBLIOGRÁFICAS}

Alvar Ezquerra, M. (2003).La enseñanza del léxico y el uso del diccionario. Madrid, Arco Libros.

Azorín Fernández (2000). Los diccionarios didácticos del español desde la perspectiva de sus destinatarios. En L.U.A., 14, 2000, pp. 19-44.

Cassany, D. (2002). Enseñar lengua. Barcelona. Gráo.

Fontanillo Merino, E., 1983. Cómo utilizar los diccionarios. Madrid, Anaya.

Hernández, H. (2000). El diccionario en la enseñanza de ELE. (Diccionarios de español para extranjeros). Actas del XI Congreso Nacional ASELE, pp. 93-103.

Hernández, H. (1993). De la teoría lexicográfica al uso del diccionario: el diccionario en el aula. En Actas del 3. ${ }^{\text {er }}$ Congreso Nacional de ASELEX, Málaga, pp. 189-199.

Maldonado, C. (1998). El uso del diccionario en el aula. Madrid, Arco Libros.

(2000). Criterios para elegir un diccionario. En: Tendencias en la investigación lexicográfica del español. El diccionario como objeto de estudio lingüístico y didáctico. Huelva: Universidad de Huelva Publicaciones.

Ministerio de Educación y Cultura (s.a.). Programas de Estudio. Castellano como lengua materna. $4 .^{\circ}, 5 .^{\circ}$ y $6 .^{\circ}$ Grados. Disponible en http://www.mec.gov.py/cms_v2/recursos/9711-programas-de-estudioactualizados. Fecha de consulta: 13/6/16

Ministerio de Educación y Cultura (s.a.). Programa de Estudio de Lengua y Literatura Castellana. $70^{\circ}, \quad 8 .^{\circ}$ y $9 .^{\circ}$ Grados. Disponible en: 
http://www.mec.gov.py/cms_v2/recursos/9711-programas-de-estudioactualizados. Fecha de consulta: 13/6/16.

Prado, J. (2000). El diccionario y la enseñanza de la lengua. En Tendencias en la investigación lexicográfica del español. El diccionario como objeto de estudio lingüístico y didáctico. Huelva: Universidad de Huelva Publicaciones.

Prado Aragonés, J. (2005). El uso del diccionario para la enseñanza de la lengua: consideraciones metodológicas. Kanina. Rev. Artes y Letras. Univ. De Costa Rica. Vol. XXIX (Especial), pp. 19-29. ISSN: 0378-0473.

(2005b). Estrategias y actividades para el uso del diccionario en el aula. Kanina. Rev. Artes y Letras. Univ. De Costa Rica. Vol. xxix (Especial), pp. 53-71. ISSN: 0378-0473.

Real Academia Española y Asociación de Academias de la Lengua Española. (2014). Diccionario de la lengua española. Madrid. Espasa. 